\title{
Histological study of corneas preserved in two new media
}

\author{
KOICHI TAMAKI, TATSUO YAMAGUCHI, EMILY D VARNELL, \\ AND HERBERT E KAUFMAN
}

From the Lions Eye Research Laboratories, LSU Eye Center, Louisiana State University Medical Center School of Medicine, New Orleans, LA, USA

SUMMARY A new corneal preserving medium (K-Sol), developed by Kaufman and others, contains purified chondroitin sulphate, TC 199, HEPES buffer, and gentamicin. Another new medium (JM) containing bicarbonate-free glucose-phosphate Ringer solution and dextran 70 has been developed in Japan. New Zealand white rabbit corneas with scleral rims were stored in each medium at $4^{\circ} \mathrm{C}$ for one or two weeks. The condition of the endothelium was evaluated histologically. Corneas preserved in both media were in good condition at the end of one week. Corneas preserved in K-Sol for two weeks showed fewer endothelial changes than similar tissue stored in JM for two weeks. Corneal swelling was also less in corneas preserved in K-Sol, than in corneas preserved in JM.

Many eye banks now use M-K medium, which was developed in the United States by McCarey and Kaufman in 1974 to preserve donor corneas until surgery. M-K medium maintained viability (as measured by temperature reversal) of rabbit corneal endothelium and generally preserved rabbit corneas for up to 14 days.' However, clinical results with human corneas suggested that storage time in $\mathrm{M}-\mathrm{K}$ medium should be limited to three or four days. ${ }^{2}$

Recently Kaufman and others developed a new corneal preservation medium (K-Sol). Corneas stored in this new medium have been tested in animal studies and used in human corneal transplants. Corneas stored in K-Sol have been successfully transplanted following storage for up to two weeks. ${ }^{34}$

Mizukawa and associates ${ }^{s}$ in 1968 developed a new liquid preserving medium, consisting of a mixture of TC-199, $\mathrm{NaHCO}_{3}, 1.5 \%$ chondroitin sulphate, inosine, adenine, adenosine, streptomycin, and penicillin. This medium was used as a corneal preserving medium in Japan. Mayes et al. ${ }^{6}$ reported that rabbit corneas stored in medium with a low bicarbonate concentration functioned better than corneas stored in medium with high bicarbonate concentration. Based on these findings a new corneal preservation medium (JM) was developed, and Manabe et al..$^{7}$ have reported that this new medium is Correspondence to Herbert E Kaufman, MD, LSU Eyc Center, 2020 Gravier Street, Suite B, New Orlcans, LA 70112, USA. an excellent and safe corneal storage medium for clinical usage.

In this study, corneas with scleral rims were stored in $\mathrm{JM}$ and in $\mathrm{K}$-Sol, and the condition of the endothelium was evaluated histologically.

\section{Materials and methods}

\section{PRESERVING MEDIUM}

The Japanese medium (JM) (Kaken Pharmaceutical Company, Hongo, Tokyo) named EP-II is based on bicarbonate-free glucose-phosphate Ringer's solution and contains dextran 70, a few electrolytes, and a mixture of streptomycin and penicillin. The medium has an osmolarity of 305 mosm and $\mathrm{pH}$ of $7 \cdot 40$ (Table 1 ).

Table 1 Japanese Medium (JM)

\begin{tabular}{|c|c|}
\hline Component & Concentration \\
\hline \multicolumn{2}{|c|}{$\begin{array}{l}\text { Glucose phosphate Ringer (HCO frec) } \\
\mathrm{No} \mathrm{CaCl}_{2} \\
\mathrm{No} \mathrm{MgCl}_{2} \cdot 6 \mathrm{H}_{2} \mathrm{O}\end{array}$} \\
\hline Dextran 70 & $3 \cdot 5 \%$ \\
\hline $\mathrm{Na} \cdot$ citrate $\cdot 2 \mathrm{H}_{2} \mathrm{O}$ & $900 \mu \mathrm{g} / \mathrm{ml}$ \\
\hline $\mathrm{MgSO}_{4} \cdot 7 \mathrm{H}_{2} \mathrm{O}$ & $218 \mu \mathrm{g} / \mathrm{ml}$ \\
\hline Streptomycin sulphate & $1000 \mu \mathrm{g} / \mathrm{ml}$ \\
\hline Potassium penicillin $\mathrm{G}$ & $200 \mathrm{units} / \mathrm{ml}$ \\
\hline & $7 \cdot 40$ \\
\hline
\end{tabular}


Table $2 \quad K$-Sol

\begin{tabular}{ll}
\hline Component & Concentration \\
\hline TC 199 & \\
HEPES buffer & $0 \cdot 25 \mathrm{M}$ \\
Chondroitin sulphatc, & $2 \cdot 5 \%$ \\
$\quad$ purified MW $>10000$ & $100 \mu \mathrm{g} / \mathrm{ml}$ \\
Gentamicin sulphate & $7 \cdot 40$ \\
pH & 310 mosm \\
\hline
\end{tabular}

K-Sol contains $2 \cdot 5 \%$ purified chondroitin sulphate (molecular weight $>10000$ ) in TC 199, 0.25 M HEPES buffer, and gentamicin sulphate (Cilco, Sandford, NC). The medium has an osmolality of 310 mosm, and a pH of $7 \cdot 40$ (Table 2 ).

\section{TISSUE}

New Zealand white rabbits were killed with an overdose of sodium pentobarbital and both eyes were immediately enucleated. Corneas with scleral rims were stored in either JM or K-Sol at $4^{\circ} \mathrm{C}$. Eight pairs of corneas were used: the right corneas were preserved in JM and the mate corneas were preserved in K-Sol. Four pairs of corneas were stored for one week, and another four pairs were stored for two weeks at $4^{\circ} \mathrm{C}$.

\section{MICROSCOPY}

At the end of the period of observation the specimens were divided into two pieces. One part was fixed immediately in $2.5 \%$ glutaraldehyde and $3 \%$ formalin with $1 / 15 \mathrm{M}$ potassium sodium phosphate buffer $(\mathrm{pH} \mathrm{7.35)}$ for 12 hours, washed in the same buffer, postfixed in buffered 1\% osmium tetroxide for 90 minutes, washed again in buffer, dehydrated in graded alcohols from $50 \%$ to $100 \%$ and propylene oxide, and embedded in Epon. Embedded specimens were sectioned with a microtome and stained with toluidine blue for light microscopy or uranyl acetate and lead citrate for transmission electron microscopy.

The other part of each cornea was fixed in $2 \cdot 5 \%$

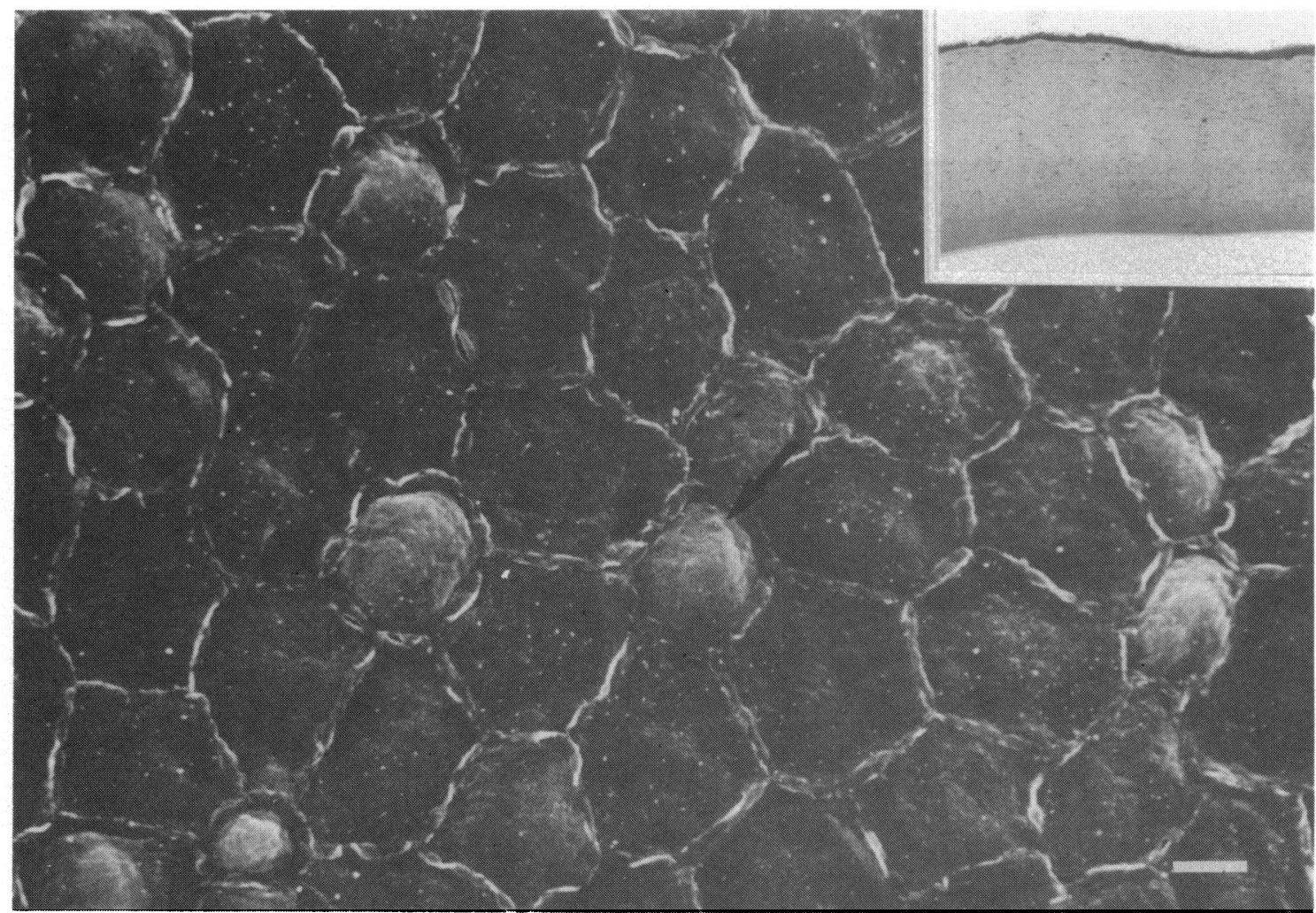

Fig. 1A JM preservation for one week. Scleral rim. Scanning electron micrograph of the corneal endothelium. Some of the endothelial cells are swollen and protruding (arrow). Normal mosaic-like appearance can be seen. Bar $=5 \mu \mathrm{m}$. Inset: Light micrograph. Corneal thickness is $0.56 \mathrm{~mm}$. Corneal swelling is prominent. The epithelial cells and stromal cells are well preserved. Toluidine blue. 


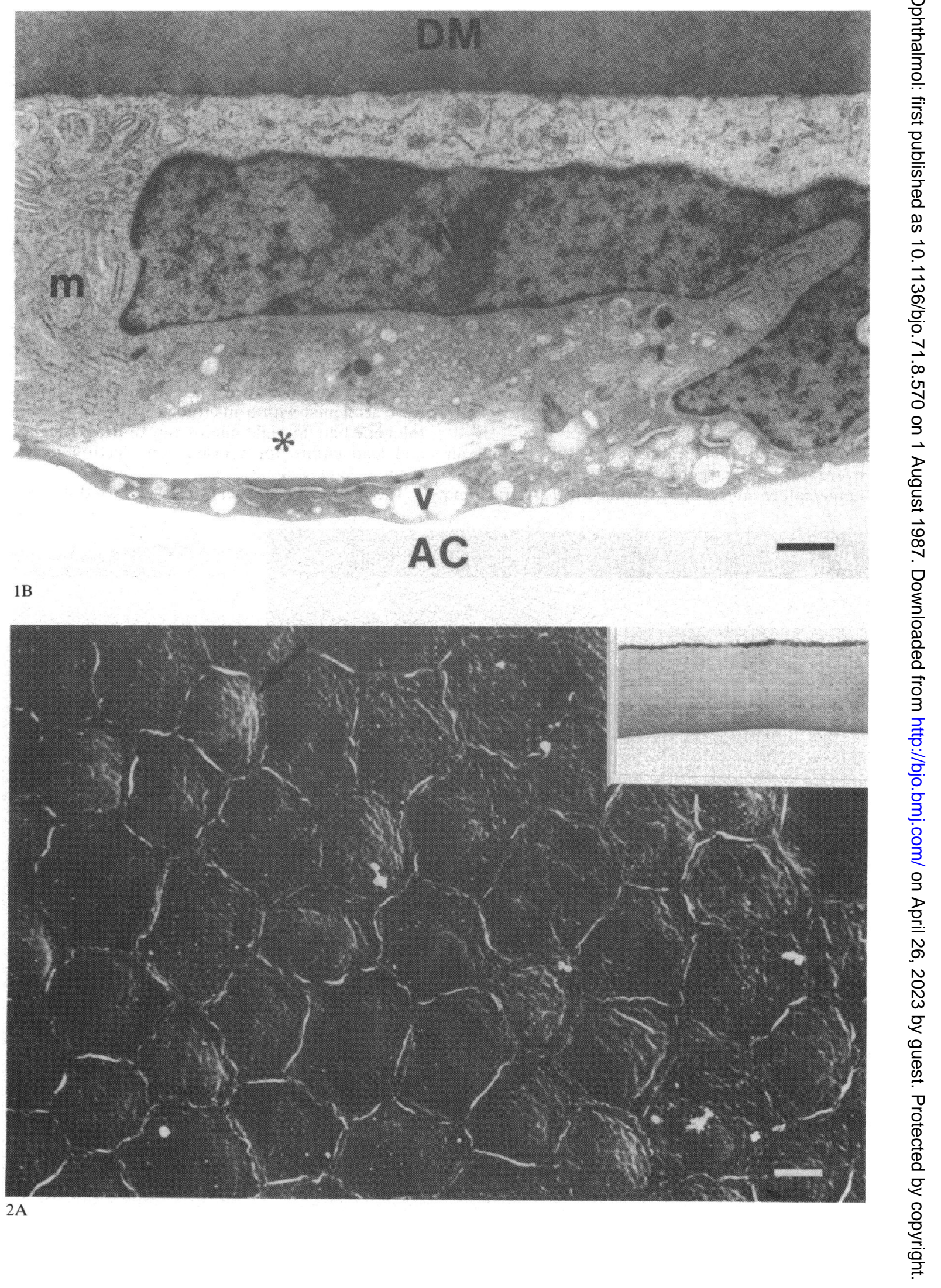




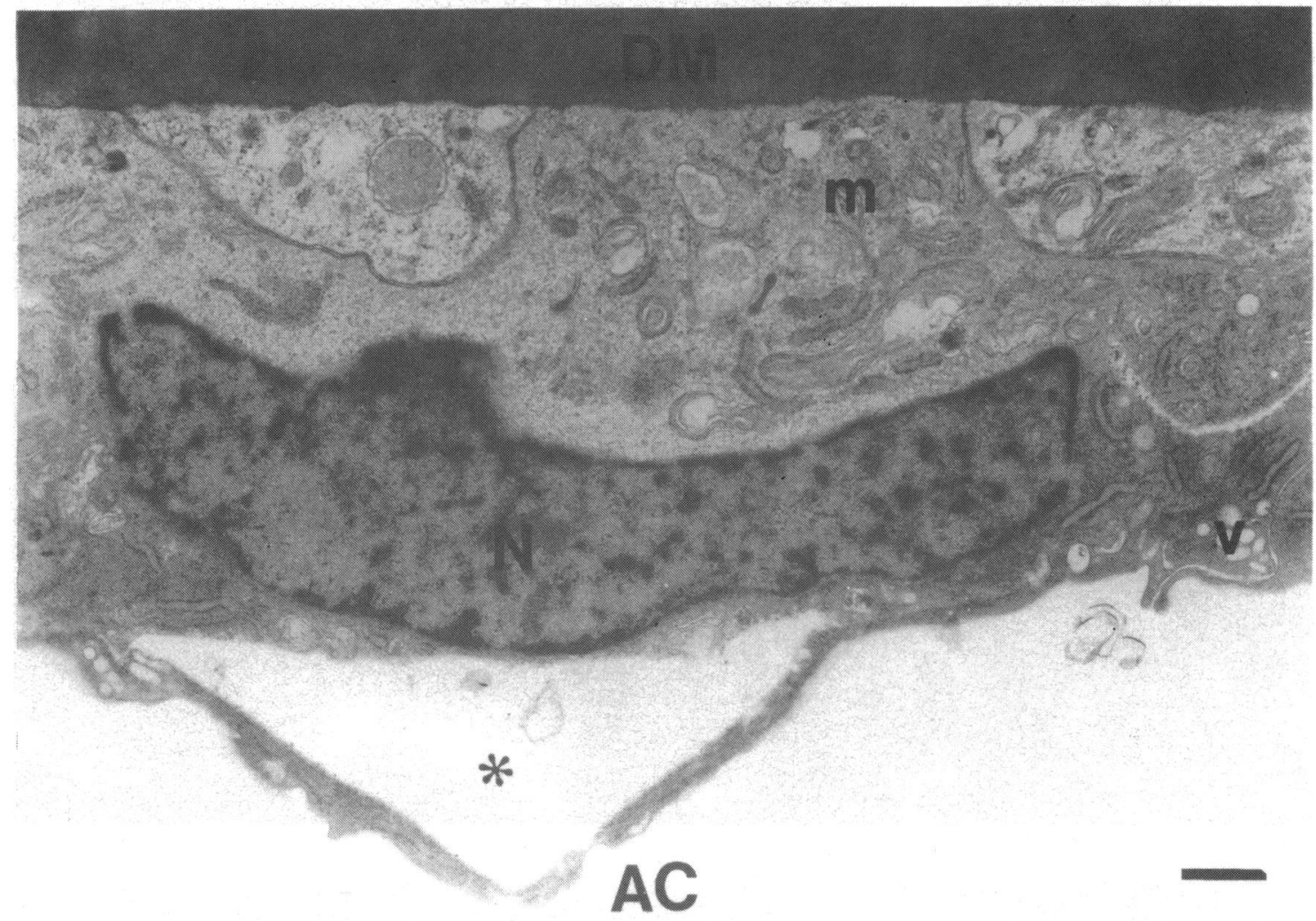

2B

glutaraldehyde and $3 \%$ formalin with potassiumsodium buffer ( $\mathrm{pH} \mathrm{7.4)} \mathrm{for} 12$ hours, dehydrated in alcohol, dried in a critical-point dryer, placed on aluminum stubs, coated with gold, and photographed by means of scanning electron microscopy. Corneal thickness was measured on light micrographs, which were enlarged 30 times.

\section{Results}

The appearance of the preserved corneas was similar in all specimens.
PRESERVATION FOR ONE WEEK

On light micrographs the average thickness of the corneas preserved in JM was $0.54 \mathrm{~mm}$ and stromal swelling was prominent (Fig. 1A, inset). The control corneal thickness was $0.31 \mathrm{~mm}$. The corneas preserved in K-Sol (Fig. 2A, inset) measured $0.39 \mathrm{~mm}$ in thickness, and no stromal swelling was seen. The epithelial cells were intact and the stromal cells were preserved in both corneas.

Both corneas appeared similar by scanning electron microscopy. A few swollen endothelial cells were seen protruding into the anterior chamber.

Fig. 1B JM preservation for one week. Scleral rim. Transmission electron micrograph of same cornea as in Fig. IA. Cleft $\left({ }^{*}\right)$ and small vacuolations (V) can be seen on the apical side. The cytoplasm is slightly less dense anterior to the nucleus. The cytoplasmic organelles are almost intact. $\mathrm{DM}=$ Descemet's membrane; $\mathrm{N}=$ nucleus; $\mathrm{AC}=$ anterior chamber; $\mathbf{M}=$ mitochondria. Bar $=0.7 \mu \mathrm{m}$.

Fig. 2A K-Sol preservation for one week. Scleral rim. Scanning electron micrograph of the corneal endothelium. A few endothelial cells (arrow) are swollen. Normal mosaic-like appearance can be seen. Bar $=5 \mu \mathrm{m}$. Inset: Light micrograph. Corneal thickness is $0.40 \mathrm{~mm}$. The stroma is not swollen. The epithelial cells and stromal cells are well preserved. Toluidine blue.

Fig. 2B K-Sol preservation for one week. Scleral rim. Transmission electron micrograph of the same corneas as in Fig. $2 A$. Cleft $\left({ }^{*}\right)$ and a few vacuolations $(\mathrm{V})$ can be seen. Cytoplasmic organelles are almost intact. DM=Descemet's membrane; $\mathrm{N}=$ nucleus; $\mathrm{M}=$ mitochondria; $\mathrm{AC}=$ anterior chamber. Bar $=0 \cdot 7 \mu \mathrm{m}$. 


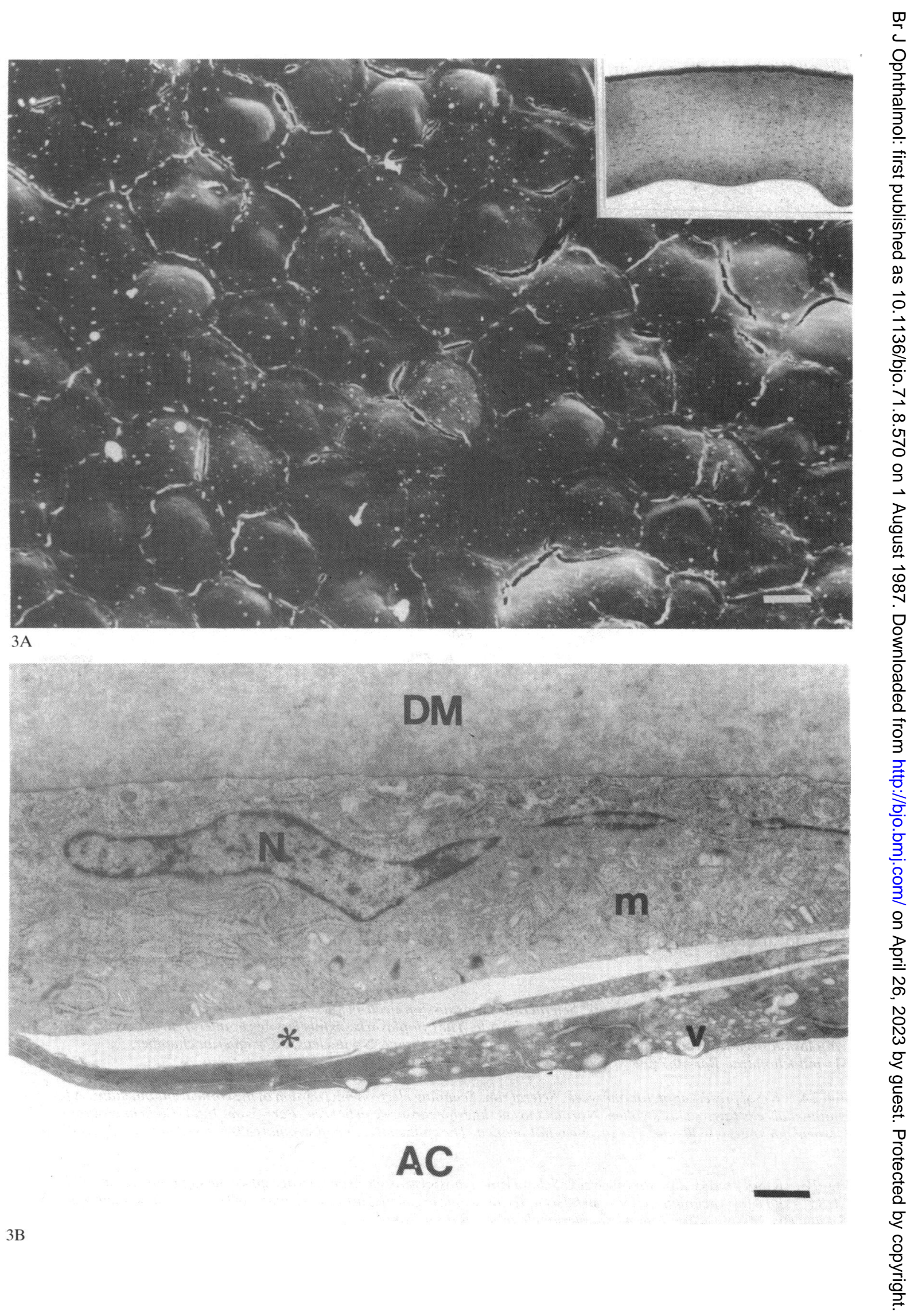




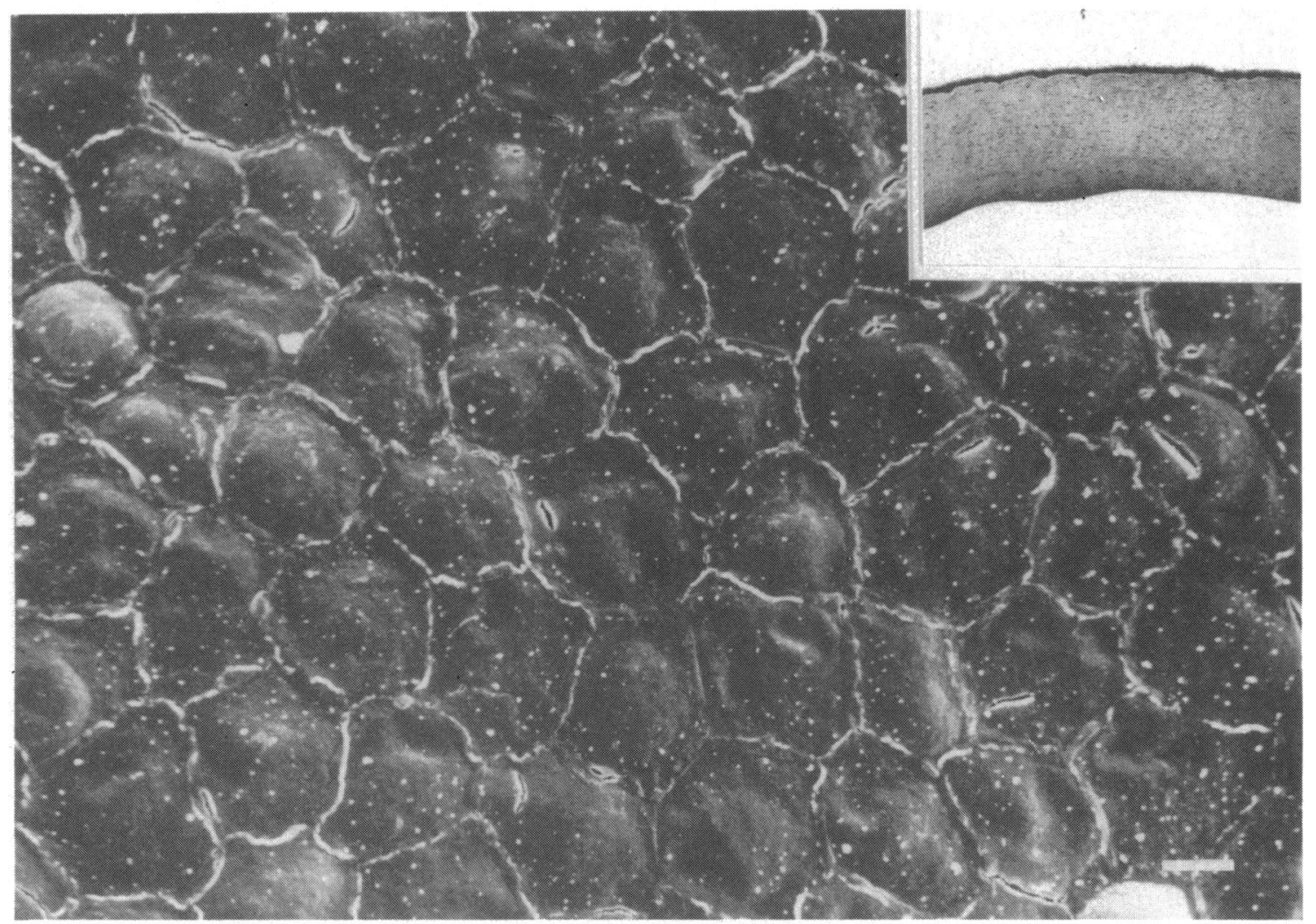

$4 \mathrm{~A}$

Intercellular cytoplasmic membranes were distinct. The mosaic-like arrangement of the hexagonal endothelial cells was nearly normal (Figs. 1A, 2A).

By transmission electron microscopy the corneas also looked similar. An endothelial cleft and small vacuolations were seen. The cytoplasm seemed less dense anterior to the nucleus. The mitochondria were somewhat swollen, but the cristae were not disrupted (Figs. 1B, 2B). The endothelial sheets were preserved in good condition.

\section{PRESERVATION FOR TWO WEEKS}

On light micrographs the average thickness of the corneas preserved in $\mathrm{JM}$ measured $0.53 \mathrm{~mm}$, and stromal swelling was prominent (Fig. 3A, inset). The thickness of the cornea preserved in $\mathrm{K}$-Sol was $0 \cdot 35$ $\mathrm{mm}$, which is almost normal (Fig. 4A, inset). The epithelial cells and stromal cells were well preserved in both corneas.

By scanning electron microscopy corneas preserved in JM showed some swollen endothelial cells protruding into the anterior chamber, and cellular pleomorphism was prominent. Several pits were seen in the intercellular junctions (Fig. 3A). The corneas preserved in K-Sol showed a few swollen endothelial cells and small pits in the cytoplasmic membrane.

Fig. 3A JM preservation for two weeks. Scleral rim. Scanning electron micrograph of the corneal endothelium. About $20 \%$ of the endothelial cells are swollen and cellular pleomorphism is prominent. Pits (arrow) can be seen on the surface of the endothelium. Mosaic-like appearance can still be seen. Bar=5 $\mu \mathrm{m}$ Inset: Light micrograph. The epithelial cells and stromal cells are well preserved. Corneal thickness is $0.54 \mathrm{~mm}$. Corneal swelling is prominent. Toluidine blue.

Fig. 3B JM preservation for two weeks. Scleral rim. Transmission electron micrograph of the cornea seen in Fig. 3 A. Large clefts $\left({ }^{*}\right)$ and small vacuolations $(\mathrm{V})$ can be seen on the apical side of the endothelium. The cytoplasmic organelles are intact. $\mathrm{DM}=$ Descemet's membrane; $\mathrm{N}=$ nucleus; $\mathrm{M}=$ mitochondria $; \mathrm{AC}=$ anterior chamber. Bar $=0 \cdot 7 \mu \mathrm{m}$.

Fig. 4A K-Sol preservation for two weeks. Scanning electron micrograph of the corneal endothelium. The intercellular cytoplasmic membranes are distinct, and the hexagonal endothelial cells demonstrate a normal mosaic-like appearance. A few swollen endothelial cells and pits can be seen. Bar $=5 \mu \mathrm{m}$. Inset: Light micrograph. Corneal thickness is 0.35 mm. No stromal swelling is seen. The epithelial cells and stromal cells are well preserved. Toluidine blue. 


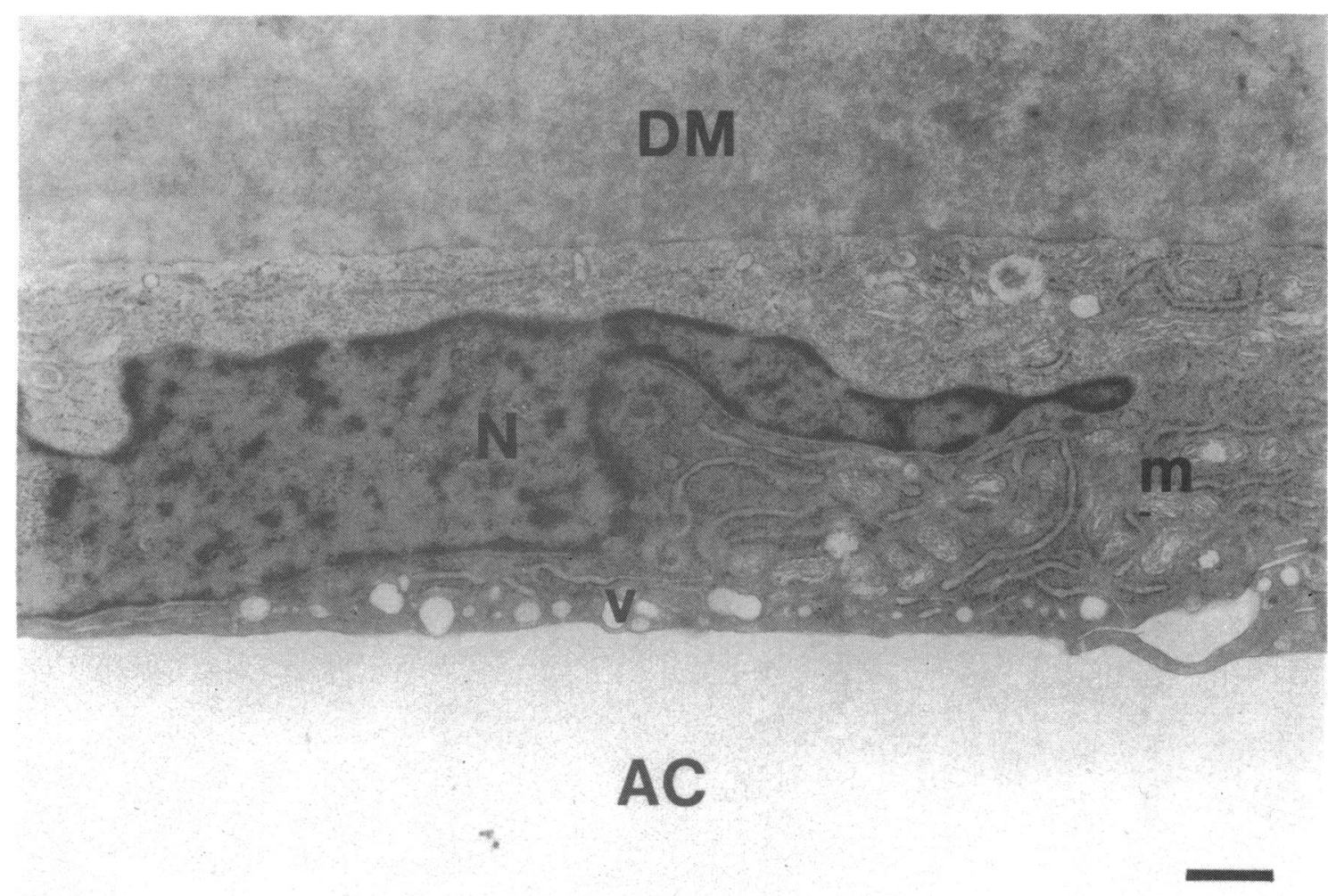

Fig. 4B K-Sol preservation for two weeks. Scleral rim. Transmission electron micrograph of the same cornea seen in Fig. $4 A$. A few small vacuolations can be seen. Cytoplasmic organelles are intact. DM=Descemet's membrane; $N=n u c l e u s ;$ $\mathrm{M}=$ mitochondria; $\mathrm{AC}=$ anterior chamber. Bar $=0.7 \mu m$.

The intercellular cytoplasmic membranes were well preserved, and the hexagonal endothelial cells demonstrated a normal mosaic-like appearance. The endothelial sheets were almost intact (Fig. 4A). By transmission electron microscopy the corneas preserved in JM showed large clefts and small vacuolations. The cytoplasmic organelles were almost normal (Fig. 3B). In the corneas preserved in K-Sol the endothelial cells were almost intact except for small vacuolations (Fig. 4B).

\section{Discussion}

JM, which contains no bicarbonate, was developed by modifying glutathione bicarbonate Ringer's solution. (GBR). ${ }^{8}$ Endothelial function is almost stopped by cooling to $4^{\circ} \mathrm{C}$. Mayes et al. ${ }^{\circ}$ reported that a preserving medium with low bicarbonate concentration intensifies this effect. Therefore, nutritional materials are not included in this medium except for glucose. In contrast, K-Sol contains tissue culture medium for corneal nutrition, though K-Sol preser- vation also reduces corneal endothelial function by cooling to $4^{\circ} \mathrm{C}$.

Because cooling of the cornea to $4^{\circ} \mathrm{C}$ stops the function of the corneal endothelium, it also triggers corneal swelling. Dextran 70 and chondroitin sulphate are both high molecular weight materials that prevent stromal swelling. ${ }^{4-11} \mathrm{JM}$ contains dextran 70 (MW 70000) and K-Sol contains purified chondroitin sulphate (MW >10000). For penetrating keratoplasty it is desirable to use grafts of normal thickness. In our experiments corneas with scleral rims preserved in K-Sol maintained normal thickness for up to two weeks. No stromal swelling was seen (Fig. 4A). However, corneas with scleral rims preserved in $\mathrm{JM}$ were thicker than those in K-Sol and stromal swelling was prominent (Fig. 3A); thus K-Sol preservation appears to be superior in preventing stromal swelling. It is believed that purified chondroitin sulphate prevents corneal swelling, as first reported by Kida. ${ }^{9}$

Characteristic changes seen by transmission electron microscopy in the endothelium were clefts, 
cytoplasmic vacuolations, and decreased cytoplasmic densities. The clefts were parallel to the cytoplasmic membrane and crescentic in shape. Small vacuolations were located on the apical side. Similar changes have been reported in the past with $4^{\circ} \mathrm{C}$ preservation. ${ }^{112}$ Sakimoto et al. ${ }^{12}$ reported that the clefts disappeared after penetrating keratoplasty. This change may be the result of the loss of endothelial function during $4^{\circ} \mathrm{C}$ preservation. The density of the cytoplasmic organelles was somewhat decreased in the endothelial cells, but the organelles were almost intact. Overall, the endothelial sheets were in good condition in both corneas preserved for two weeks, though nearly all the endothelial cell nuclei were swollen.

By scanning electron microscopy the changes seen in endothelial cells preserved in both media for one week were negligible. Endothelial cell size was normal and the cytoplasmic membranes were almost intact (Figs. 1B, 2B). Corneas preserved for two weeks showed no endothelial cell loss. The hexagonal cells were well preserved. However, a few endothelial cells were enlarged, and endothelial pleomorphism was prominent. Endothelial swelling and pits in the cytoplasmic membrane were also visible, though the cytoplasmic pits were not confirmed by transmission electron microscopy. These endothelial changes (pleomorphism and pits) were more prominent in the corneas preserved in JM. Mizukawa et al. ${ }^{5}$ reported that even at $4^{\circ} \mathrm{C}$ the function of the cornea cannot be stopped completely; therefore a preserving medium should contain some nutritional additives. It is conceivable that lack of nutrition results in more changes in corneas preserved in JM, and that chondroitin sulphate exerts a beneficial effect on corneal endothelial cells preserved in K-Sol, as reported by Lindstrom and associates. $^{13}$

$\mathrm{K}$-Sol preserved corneas have been used in corneal transplantation in humans with good results. ${ }^{4}$ Human corneal endothelium degenerates much faster than that of rabbits, ${ }^{6}$ and the reproductive power of the endothelium in the rabbit is much greater than in humans. Therefore it seems likely that the results obtained with rabbit corneas in this study are better than those obtained with human tissue. However, it may also be true that some histological changes that may occur in human tissue during storage may be reversible when the cornea is transplanted into the eye. In this study, although the corneas with scleral rims preserved for two weeks in both K-Sol and JM remained in good condition, somewhat better results were obtained with K-Sol.

Supported in part by PHS grants EYO2580 and EYO2377 from the National Eye Institute, National Institutes of Health, Bethesda, MD.

\section{References}

1 McCarey BE, Kaufman HE. Improved corneal storage. Invest Ophthalmol Vis Sci 1974; 13: 165-73.

2 Van Horn DL, Schultz RO. Corneal preservation: recent advances. Surv Ophthalmol 1977; 21: 301-12.

3 Kaufman HE, Varnell ED, Kaufman S. Chondroitin sulfate in a new cornea preservation medium. Am J Ophthalmol 1984; 98: 112-14.

4 Kaufman HE, Varnell ED, Kaufman S, et al. K-Sol corneal preservation. Am J Ophthalmol 1985; 100: 299-304.

5 Mizukawa T, Manabe R. Recent advances in keratoplasty with special reference to the advantage of liquid preservation. Folia Ophthalmol Jpn 1968; 19: 1310-8.

6 Mayes KR, Graham MV, Hodson S. The deleterious effects of exogenous bicarbonate on the rabbit cornea undergoing prolonged refrigerated storage. Exp Eye Res 1978; 26: 555-60.

7 Manabe R, Kinoshita S, Itoi M, Tanishima T, Kodama Y. Clinical trials of new eye preserving medium (EP-II). Folia Ophthalmol Jpn 1984; 35: 1263-5.

8 Morimoto K, Kikkawa Y, Morisaka K, et al. A new corneal storage medium. Folia Ophthamol Jpn 1983; 34: 1641-9.

9 Kida S. Studies on the preservation of excised bovine cornea. Folia Ophthalmol Jpn 1960; 11: 29-36.

10 Tanishima T, Matsumura U, Masuda K. The effect of new intraocular irrigating solution on the rabbit corneal endothelium. Nippon Ganka Gakkai Zasshi 1984; 88: 829-37.

11 Bigar F, McCarey BE, Kaufman HE. Improved corneal storage: penetrating keratoplasties in rabbits. Exp Eye Res 1975; 20: 219-22.

12 Sakimoto T, Valenti J, Itoi M, Kaufman HE. Intermediate-term corneal storage. Invest Ophthalmol Vis Sci 1974; 13: 219-28.

13 Lindstrom RL, Skelnik DL, Mindrup EA, Doughman DJ. Organ culture corneal preservation with chondroitin sulfate. ARVO Abstract. Invest Ophthalmol Vis Sci 1984; 25 (suppl): 266.

Accepted for publication 9 September 1986. 